\title{
Breastfeeding Awareness and Practices in Abakaliki, Southeast, Nigeria
}

\section{Matthew Igwe Nwali*, Joseph Agboeze, Brown Nnamdi Ejikeme, Okechukwu Bonaventure Anozie, Blessing Onwe}

Department of Obstetrics and Gynecology, Federal Teaching Hospital Abakaliki, Abakaliki, Nigeria

Email: ^nwaligwe@live.com,dragbeze@yahoo.com

How to cite this paper: Nwali, M.I., Agboeze, J., Ejikeme, B.N., Anozie, O.B. and Onwe, B. (2016) Breastfeeding Awareness and Practices in Abakaliki, Southeast, Nigeria. Open Journal of Obstetrics and Gynecology, 6, 861-873.

http://dx.doi.org/10.4236/ojog.2016.613104

Received: November 12, 2016 Accepted: December 20, 2016

Published: December 23, 2016

Copyright $\odot 2016$ by authors and Scientific Research Publishing Inc. This work is licensed under the Creative Commons Attribution International License (CC BY 4.0).

http://creativecommons.org/licenses/by/4.0/ (c) (i) Open Access

\section{Abstract}

Background: The Federal Teaching Hospital is the only tertiary hospital in Ebonyi State Nigeria. It receives referrals from the general and private hospitals, primary health centers in the state as well as the surrounding state. Breast feeding is a social norm among the indigenes of the state hence practiced commonly. Aim: The study was aimed at determining the knowledge and practice of exclusive breast feeding among the women presenting in the hospital. Methods: This was a cross-sectional study in the maternity unit of the hospital over three months' period from March to May 2015. A structured data sheet was administered to each mother presenting in the maternity unit of the hospital and willing to participate which were consecutively recruited into the study. Results: A total of 500 mothers participated in the study. About $98.4 \%$ were aware of exclusive breast feeding while $90.2 \%$ practiced it for different reasons and duration. Only 76.4\% practiced it for a period of 4 - 6 months. Majority of the mothers (90.0\%) got the information about exclusive breast feeding from the hospital. Times of initiation of breast feeding after delivery were $38.2 \%$ within 30 minutes and $33.2 \%$ an hour respectively. Seventy six percent of the mothers' breastfed on demand. About 91.6\% were willing to practice exclusive breast feeding for subsequent babies. Surprisingly $10.2 \%$ of the mothers discarded their colostrums. Practice of exclusive breast feeding was significantly related to educational status and occupation. Conclusion: Greater awareness and practice of exclusive breastfeeding has been achieved but more still needed to be done especially about the time of initiation, giving of colostrums and the duration of exclusive breast feeding since up to $10.4 \%$ of the participants still discarded their colostrums particularly those that delivered outside the hospital.

\section{Keywords}

Breastfeeding Practices, Abakaliki, Southeast, Nigeria 


\section{Introduction}

Breastfeeding is as old as man and is the safest and best child rearing practice in terms of infant feeding. This practice was being relegated to the background as breast milk substitutes were taking its place. The importance of breastfeeding cannot be overemphasized. The breast milk is hygienic, safe, cheap, readily available and affordable. It supplies all the necessary water and nutrients adequate for healthy growth and development in the first six months of life as well as the necessary immunity for some common infections. It does not place undue stress on the immature intestines, liver and kidneys of the newborn baby. For the breastfeeding mother, it serves as a method of family planning especially when done on demand and exclusive. Studies have shown that breastfed babies are less likely to suffer most serious illnesses [1] [2] [3] [4].

The provision of adequate nutrition during infancy and early childhood is a basic requirement for the development and promotion of optimum growth, health and behavior of the child. Adequate nutrition means intake and utilization of enough energy and nutrients to maintain wellbeing, health and productivity of an individual. The period of birth to two years of age is recognized as a critical period for which adequate nutrition should be provided for the child to achieve optimum development and full potential [5].

The World Health Organization in 2010 reported worldwide prevalence or rate of Exclusive Breastfeeding as 35\% from 0 - 5 months [6]. The rate of $19.1 \%$ was reported in Greece [7], 36\% in Bangladesh among rural women and 10\% in India [8] [9]. The exclusive breastfeeding awareness in Ethiopia and Tanzania were $93.6 \%$ and $58.8 \%$ respectively while the prevalence rate in Ethiopia was 59.3\% [10] [11].

In Nigeria, the immediate causes of malnutrition in the first two years of life are inappropriate breastfeeding and complementary feeding practices coupled with high rates of infections. About $60 \%$ of all childhood deaths are reportedly due to underlying malnutrition [5]. The rate of exclusive breastfeeding in the first six months of life was reported as between $15 \%$ to $17 \%$ (NFCNS 2001-3, NDHS 2003). Over 50\% of Nigerian infants are given complementary food too early which is often of poor nutritional value in terms of energy, protein and micronutrients. Based on these and the innocent declaration as well as the baby friendly initiative adopted in 2005, there was policy development on Infant and Young Child Feeding (IYCF) in Nigeria. The policy is aimed at:

1) Promoting, protecting and supporting exclusive breastfeeding.

2) Creating and sustaining positive images of breastfeeding etc. [5].

Some studies have shown improvement but there is still much work to be done. Currently, scientific evidence overwhelmingly indicates that breastfeeding is the optimal method of infant feeding and should be promoted and supported to ensure the best health for women and children. Breastfeeding is the single most powerful and well documented preventive modality available to health care providers to reduce the risk of common causes of infant morbidity. Significantly, lower rates of diarrhea, otitis media, lower respiratory tract infections, type $1 \& 2$ diabetes, childhood leukemia, necrotizing 
enterocolitis and sudden infant death syndrome occur among those who were breastfed [12]. Women who breastfeed have lower risk of type 2 diabetes, breast and ovarian cancers [13]. Recent evidence also suggests that reduction in the risk for cardiovascular and other related diseases may be added to the benefits of breastfeeding for women [14]. Recently breastfeeding has been found to play fundamental role in preventing childhood overweight and development of later obesity. Recent analysis showed that breastfeeding consistently reduced risk for overweight and obesity and that the greatest protection is seen when breastfeeding is exclusive for more than three months [12] [13] [14].

There is no previous study in this center on breastfeeding practices. This study is aimed at determining the awareness and breast feeding practices among mothers presenting at the maternity unit of the Federal Teaching Hospital Abakaliki.

\section{Materials and Methods}

This cross-sectional descriptive study was prospectively carried out at the maternity unit of the Federal Teaching Hospital Abakaliki, Nigeria between March and May, 2015. The purpose and methods of the study were explained to the mothers in details and informed consent obtained prior to enlisting them into the study. The exclusion criteria were those that refuse consent and HIV positive mothers.

The study population comprised of consecutively recruited mothers in the maternity unit (postnatal and antenatal wards and antenatal clinic). An open-ended questionnaire designed for the study administered to the mothers. Socio-demographic information including the age of the mothers, maternal occupation, educational status, parity, religion, marital status were obtained. The details of breastfeeding and weaning practices were recorded.

\subsection{Ethical Issues}

The research and ethics committee of the Federal Teaching Hospital approved the study protocol. Informed consent was obtained from the participants and given the option to opt out at any time if they do not wish to continue. Those who do not practice exclusive breastfeeding were counseled adequately on the importance for both the mother and the baby. The importance of colostrums and early initiation of breastfeeding were also emphasized with particular attention to those that discarded their colostrums.

\subsection{Sample Size Calculation}

A similar study in the country reported the awareness of $67.1 \%$. This was chosen to calculate the minimum sample size using the following formula:

$$
n=z^{2} P(1-P) / d^{2}
$$

where

$$
n=\text { The required minimum sample size, }
$$


$Z=$ A number relating to the degree of confidence $=1.96$,

$P=$ The proportion of awareness from a similar study $=67.1 \%$,

$d=$ The tolerable error for the study $=5 \%$.

Thus the estimated minimum sample size was 339 but we analyzed 500 clients.

The information obtained was recorded in the data collation sheet designed for the study. The coded data were fed into the computer using epi info program (2008) of CDC Atlanta USA 3.5.1 version and analysis done. A $P$ value less than 0.05 was considered significant.

\section{Results}

A total of 500 mothers participated in the study. The mean age in the study was $29.4 \pm$ 5.4 years and ranged between 18 - 48 years. The median parity was $2.0 \pm 1.4$ and ranged between Para 1-Para 9. Majority of the mothers were aged between 20 - 39 years, more of Para 1 - 4 and hard tertiary education. Thirty six percent (180/500) of the mothers were civil servants and $96.0 \%(480 / 500)$ were married. Ninety seven percent of them were Christians. Sixty percent (301/500) had their last delivery in a tertiary hospital and 85.0\% (425/500) hard spontaneous vertex delivery (Table 1).

Awareness of exclusive breastfeeding (EBF) was 98.4\% (492/500) while 90.2\% (451/ $500)$ practiced it for different reasons and duration. About $76.4 \%$ practiced EBF for duration of 4 - 6 months. Major source of information about EBF was from the hospital $90.0 \%$ (450/500). Times of initial of breastfeeding after birth were mostly within 30 minutes (38.2\%) and an hour (33.2\%). Complementary food was mostly introduced after 6 months of birth. Approximately $76 \%$ of the mothers breastfed on demand and baby sucks for 15 - 20 minutes (35.6\%) or as long as the baby wants (28.4\%). Majority of the mothers (72.4\%) practiced EBF for all their babies. About $63.2 \%$ of them believed that breast milk was enough for the baby during the EBF period and $91.6 \%$ are willing to do it again for their subsequent babies. Surprisingly $10.4 \%$ of the mothers discarded their colostrums and $70.6 \%$ breastfed their babies for a year, (Table 2).

Majority of the mothers breastfed as a social norm (72.6\%) as well as for healthy growth of the baby (70.0\%) (Table 3). Some of the mothers (19.4\%) discontinued EBF because they believe baby remains hungry and $17.8 \%$ because of return to work or school but majority of them $76.6 \%$ discontinued at the right time (Table 4). Educational status and occupation were the variables that had statistical significant relationship with the practice of EBF $\left(\mathrm{X}^{2}=6.0486\right), P$ value $=0.0486$ and $\mathrm{X}^{2}=13.2923, P$ value $=$ 0.0386 respectively) (Table 5 ). The mode of delivery has significant relationship with the time of initiation of breastfeeding after birth $\left(\mathrm{X}^{2}=120.9952, P\right.$ value $\left.=0.0000\right)$. The place of delivery had statistically significant relationship with discarding of the colostrums $\left(\mathrm{X}^{2} 132.2072, P\right.$ value $\left.=0.0000\right)$.

Educational level also played a significant role in the duration of $\mathrm{EBF}\left(\mathrm{X}^{2}=27.7582\right.$, $P$ value $=0.0000)$. Age of mother also played a significant role in the total duration of breastfeeding $\left(\mathrm{X}^{2}=22.9749, P\right.$ value $\left.=0.0008\right)$ as well as parity $\left(\mathrm{X}^{2}=12.3825, P\right.$ value $=$ $0.0147)$ and occupation $\left(\mathrm{X}^{2}=23.0868, P\right.$ value 0.0270$)$ (Table 6). 
Table 1. Socio demographic characteristics of responses.

\begin{tabular}{|c|c|c|}
\hline Variable & $\mathrm{N}=500$ & $\%$ \\
\hline \multicolumn{3}{|l|}{ Age } \\
\hline$\leq 19$ & 10 & 2 \\
\hline $20-29$ & 253 & 50.6 \\
\hline $30-39$ & 212 & 42.4 \\
\hline$\geq 40$ & 25 & 5 \\
\hline \multicolumn{3}{|l|}{ Parity } \\
\hline $1-4$ & 462 & 92.4 \\
\hline$\geq 5$ & 38 & 7.6 \\
\hline \multicolumn{3}{|l|}{ Education } \\
\hline None & 55 & 11 \\
\hline Secondary school & 136 & 27.2 \\
\hline Tertiary & 309 & 61.8 \\
\hline \multicolumn{3}{|l|}{ Occupation } \\
\hline Civil servant & 180 & 36.0 \\
\hline Student & 49 & 9.8 \\
\hline Trader & 97 & 19.4 \\
\hline House wife & 79 & 15.0 \\
\hline Self education & 36 & 7.2 \\
\hline Teacher & 43 & 8.6 \\
\hline Farmer & 16 & 3.2 \\
\hline \multicolumn{3}{|l|}{ Marital status } \\
\hline Single & 20 & 4.0 \\
\hline Married & 480 & 96.0 \\
\hline \multicolumn{3}{|l|}{ Religion } \\
\hline Christian & 485 & 97.0 \\
\hline Islam & 10 & 2.0 \\
\hline Others & 5 & 1.0 \\
\hline \multicolumn{3}{|l|}{ Place of delivery } \\
\hline Traditional birth attendant & 25 & 5.0 \\
\hline Primary healthcare/Maternity home & 52 & 10.4 \\
\hline Private Hospital & 74 & 14.8 \\
\hline Second centre & 48 & 9.6 \\
\hline Tertiary centre & 301 & 60.2 \\
\hline \multicolumn{3}{|l|}{ Mode of delivery } \\
\hline Spontaneous Vertex Delivery & 425 & 85.0 \\
\hline Assisted Vaginal Delivery & 14 & 2.8 \\
\hline Caesarean Section & 61 & 12.2 \\
\hline
\end{tabular}


Table 2. Practice of breastfeeding.

\begin{tabular}{|c|c|c|}
\hline & No $=50$ & $\%$ \\
\hline \multicolumn{3}{|l|}{ Awareness of exclusive Breastfeeding } \\
\hline Aware & 492 & 98.4 \\
\hline Not aware & 8 & 1.6 \\
\hline \multicolumn{3}{|c|}{ Source of information on Exclusive Breastfeeding } \\
\hline Relatives & 87 & 17.4 \\
\hline Church & 105 & 21.0 \\
\hline Friends & 138 & 27.6 \\
\hline Hospital & 450 & 90.0 \\
\hline Media & 223 & 44.6 \\
\hline \multicolumn{3}{|l|}{ Practice of Exclusive Breastfeeding } \\
\hline Practiced Exclusive Breastfeeding & 451 & 90.2 \\
\hline Did not practice & 49 & 9.8 \\
\hline \multicolumn{3}{|l|}{ Complimentary food } \\
\hline From birth or within 4 weeks & 45 & 9.0 \\
\hline$\leq 3$ months & 73 & 14.6 \\
\hline 4 months & 80 & 16.0 \\
\hline 5 months & 86 & 17.2 \\
\hline 6 months & 216 & 43.2 \\
\hline \multicolumn{3}{|l|}{ Time initiated } \\
\hline Within 30 minutes & 191 & 38.2 \\
\hline In an hour & 160 & 33.2 \\
\hline Within 2 hours & 88 & 17.6 \\
\hline$* 3-5$ hours & - & \\
\hline 6 hours & 26 & 5.2 \\
\hline$\star 7-11$ hours & - & \\
\hline 12 hours & 14 & 2.8 \\
\hline${ }^{\star} 13-23$ hours & - & \\
\hline 24 hours & 15 & 3.0 \\
\hline \multicolumn{3}{|l|}{ Frequency } \\
\hline 2 hourly & 43 & 8.6 \\
\hline 3 hourly & 46 & 9.2 \\
\hline 8 - 5 hourly & - & \\
\hline 6 hourly & 6 & 1.2 \\
\hline On demand & 379 & 75.8 \\
\hline When baby wakes & 26 & 5.2 \\
\hline \multicolumn{3}{|l|}{ Duration per feed } \\
\hline$\leq 15$ minutes & 46 & 9.2 \\
\hline 15 - 20 minutes & 178 & 35.6 \\
\hline $21-25$ minutes & 90 & 18.0 \\
\hline 26 - 30 minutes & 44 & 8.8 \\
\hline As long as baby sucks & 142 & 28.4 \\
\hline \multicolumn{3}{|l|}{ Number of children Exclusively Breastfed } \\
\hline All & 362 & 72.4 \\
\hline Some & 89 & 17.8 \\
\hline None & 49 & 9.8 \\
\hline \multicolumn{3}{|l|}{ Enough for baby } \\
\hline Yes & 316 & 63.2 \\
\hline
\end{tabular}




\section{Continued}

$$
\text { No }
$$

\section{Willing to do it again}

Yes

No

Colostrums

Given

Discarded

Total duration of Breastfeeding

$\leq 11$ months

A year

Up to 2 years
184

36.8

458

91.6

42

8.4

448

89.6

52

10.4

Table 3. Reason for breastfeeding.

\begin{tabular}{ccc}
\hline Reason & Number & $\%$ \\
\hline Child spacing & 98 & 19.6 \\
Easy/comfortable & 136 & 27.2 \\
Encouragement from relatives & 141 & 28.2 \\
Healthy growth of baby & 350 & 70.0 \\
Immunity & 267 & 53.4 \\
Pressure from relatives & 15 & 3.0 \\
Return the body to normal & 64 & 12.8 \\
Social norm & 363 & 72.6 \\
\hline
\end{tabular}

Table 4. Reason for discontinuation exclusive of breastfeeding.

\begin{tabular}{ccc}
\hline Reason & Number & $\%$ \\
\hline Baby continues to be hungry & 97 & 19.4 \\
Baby refused & 23 & 4.6 \\
Baby islosing weight & 6 & 1.2 \\
Became pregnant & 23 & 4.6 \\
Inadequate milk production & 14 & 2.8 \\
Lack of support (husband) & 5 & 1.0 \\
Maternal health problem & 20 & 4.0 \\
Pain in the breast & 4 & 0.8 \\
Return to work/school & 89 & 17.8 \\
Time to discontinue & 383 & 76.6 \\
Too tiring & 33 & 6.6 \\
\hline
\end{tabular}


Table 5. Demographic characteristics/practice of Exclusive breastfeeding.

\begin{tabular}{|c|c|c|c|c|}
\hline \multirow{2}{*}{ characteristics } & \multicolumn{2}{|c|}{ practiced EBF } & \multirow{2}{*}{$\mathrm{X}^{2}$} & \multirow{2}{*}{$P$-value } \\
\hline & Yes & No & & \\
\hline \multicolumn{5}{|l|}{ Age } \\
\hline$\leq 19$ & 7 & 3 & & \\
\hline $21-29$ & 226 & 27 & & \\
\hline $30-39$ & 195 & 17 & & \\
\hline$\geq 40$ & 23 & 2 & 5.6861 & 0.1279 \\
\hline \multicolumn{5}{|l|}{ Parity } \\
\hline $1-4$ & 46 & & & \\
\hline$\geq 5$ & 35 & 3 & 3.8126 & 0.1486 \\
\hline \multicolumn{5}{|l|}{ Education } \\
\hline None/primary & 45 & 10 & & \\
\hline Secondary & 121 & 15 & & \\
\hline Tertiary & 285 & 24 & 6.0486 & 0.0486 \\
\hline \multicolumn{5}{|l|}{ Occupation } \\
\hline Civil servant & 170 & 10 & & \\
\hline Student & 44 & 5 & & \\
\hline Trader & 79 & 18 & & \\
\hline House wife & 70 & 9 & & \\
\hline Self Employed & 34 & 2 & & \\
\hline Teacher & 39 & 4 & & \\
\hline Farmer & 15 & 1 & 13.2923 & 0.0386 \\
\hline \multicolumn{5}{|l|}{ Marital status } \\
\hline Single & 16 & 4 & & \\
\hline Married & 435 & 85 & 1.3974 & 0.0793 \\
\hline
\end{tabular}

\section{Discussion}

There was high awareness (98.4\%) and practice (90.2\%) of exclusive breastfeeding among the participants in this study. The awareness was much higher than previous reports from different parts of the country which ranged between $35.9 \%-71.3 \%$ [15] [16] [17]. This shows that more people are becoming aware of exclusive breastfeeding as there is wide spread information available for the mothers. It may also mean that more of the mothers now have access to antenatal care services and skilled attendant at birth who educated them on breastfeeding. This level of awareness may also be because the study was carried out in a tertiary hospital. About $90.2 \%$ of the mothers practiced exclusive breastfeeding for different duration, but $76.4 \%$ practiced it between 4 - 6 months. This is also higher than previous reports from different parts of the country which ranged between $10.2 \%$ - 61\% [16]-[21]. This also may be due to increased 
Table 6. Variables that influence breastfeeding practice.

\begin{tabular}{|c|c|c|c|c|c|c|}
\hline \multirow{2}{*}{ Variables } & \multicolumn{4}{|c|}{ Mode of delivery } & \multirow{2}{*}{$\mathrm{X}^{2}$} & \multirow{2}{*}{$P$-value } \\
\hline & SVD & AVD & \multicolumn{2}{|c|}{$\mathrm{C} / \mathrm{S}$} & & \\
\hline \multicolumn{7}{|l|}{ Initiation time } \\
\hline Within 30mins & 182 & 1 & \multicolumn{2}{|c|}{8} & & \\
\hline An hour & 149 & \multicolumn{2}{|l|}{8} & 9 & & \\
\hline 2 hours & 68 & \multicolumn{2}{|l|}{4} & 16 & & \\
\hline 6 hours & 11 & \multicolumn{2}{|l|}{1} & 14 & & \\
\hline 12 hours & 4 & \multicolumn{2}{|l|}{-} & 10 & & \\
\hline 24 hours & 11 & - & \multicolumn{2}{|c|}{4} & 120.9952 & 0.0000 \\
\hline \multirow[b]{2}{*}{ Colostrums } & \multicolumn{4}{|c|}{ Place of delivery } & & \\
\hline & TBA & $\mathrm{PH}$ & ${ }^{\star} \operatorname{Sec}$ & ${ }^{\star}$ Tert & & \\
\hline Given & 9 & 69 & 47 & 291 & & \\
\hline Discontinued & 16 & 5 & 1 & 10 & 132.2072 & 0.0000 \\
\hline Eduction lour & Dur & of Exclusive & astfeed & & & \\
\hline cucalon leves & Within & 1 month $\leq 3$ & & oths & & \\
\hline None/primary & 4 & 21 & & & & \\
\hline Secondary & 14 & 21 & & & & \\
\hline Tertiary & 19 & 36 & & & 27.7582 & 0.0000 \\
\hline 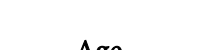 & & uration of $\mathrm{Br}$ & feedin & & & \\
\hline nge & $<1$ year & 1 year & & & & \\
\hline$\leq 19$ & 4 & 6 & & & & \\
\hline $20-29$ & 15 & 174 & & & & \\
\hline $30-39$ & 11 & 156 & & & & \\
\hline$\geq 40$ & 1 & 17 & & & 22.9749 & 0.0008 \\
\hline Parity & & & & & & \\
\hline $1-4$ & 31 & 320 & & & & \\
\hline$\geq 5$ & - & 33 & & & 12.3825 & 0.0147 \\
\hline Occupation & & & & & & \\
\hline Civil servant & 13 & 141 & & & & \\
\hline Student & 3 & 40 & & & & \\
\hline Trader & 7 & 61 & & & & \\
\hline House wife & 5 & 51 & & & & \\
\hline Self employed & 2 & 22 & & & & \\
\hline Teacher & 1 & 28 & & & & \\
\hline Farmer & - & 10 & & & 23.0868 & 0.0270 \\
\hline
\end{tabular}

Note: SVD $=$ Spontaneous Vertex Delivery, AVD $=$ Assisted Vaginal Delivery, C/S $=$ Caesarean Section, TBA $=$ Traditional Birth Attendant, $\mathrm{PHC}=$ Primary Health Centre, $\mathrm{PH}=$ Private Hospital, ${ }^{\star}$ Secondary Health Centre and Tertiary Health Centre. 
awareness and previous experience by the mothers, increased antenatal care and access to skilled birth attendants at delivery. Major source of information was from the hospital (health workers) which was $90.0 \%$ and is similar to previous report of $82.1 \%$ [15].

The mean age in the study was $29.4 \pm 5.4$ years. This compares with previous report of $27.4 \pm 5.9$ years [16]. Age did not show significant association to practice of exclusive breastfeeding. This was different from the previous study which found a significant relationship between age and practice of exclusive breastfeeding [16]. Age however showed significant association with total duration of breastfeeding as older women were more likely to breastfeed for a longer period. They was no significant association between parity and practice of exclusive breastfeeding but was significantly associated with total duration of breastfeeding as the mothers of higher parity were more likely to breastfeed for a longer period. Only occupation and level of education had significant association with the practice of exclusive breastfeeding. This was similar to previous studies [16]. Education also played a very significant role in the duration of exclusive breastfeeding. Mothers with higher level of education were more likely to breastfeed exclusively for 4 - 6 months. This may be because they have better understanding of the concept and also use it as a form of post partum contraception.

Only $38.2 \%$ of the mothers initiated breastfeeding within 30 minutes of delivery. This is low for a baby friendly facility. This was also lower than previous studies in the country which reported $61 \%$ for designated baby friendly hospital and $39 \%$ from undesignated hospital [21]. This may be because of the general believe among the mothers that breast milk does not flow soon after delivery. This may also be due to the inclusion of unbooked mothers and those that delivered outside the hospital but presented in the facility for one reason or the other during the study period. It may also be due to exhaustion and discomfort after delivery which proper counseling can take care of. The mode of delivery also played a very significant role on the time of initiation of breastfeeding. Mothers who had spontaneous vertex delivery were more likely to initiate within 30 minutes of delivery.

Some of the mothers (10.4\%) still discarded their colostrums for various reasons. This was however lower than previous reports in the country [15]. Some believe it is harmful to baby, dirty and infected. Others believed it is witch milk and is bad so should not be given to the baby. Some were told not to give by their aged mother or traditional birth attendants. The place of delivery played a very significant role in the discarding of colostrums. This was similar to previous reports [15].

Some of the women discontinued exclusive breastfeeding due to various reasons majority of which was at the right time. Some however discontinued because they believed that baby continues to be hungry (17.8\%), returned to work or school (17.8\%). These were lower than previous reports of $29.0 \%$ [19] and $20.8 \%$ [16] and $24.0 \%$ respectively. This may be because the mothers now know better feeding methods, positions, more are breastfeeding on demand and feeds baby till satisfaction.

\section{Conclusion}

Greater awareness has been achieved and more mothers are practicing exclusive breast- 
feeding.

\section{Acknowledgements}

We appreciate the resident doctors, the management and staff of the maternity unit of the Federal Teaching Hospital Abakaliki, for their support and assistance in data collection for this study.

\section{Recommendation}

More work is needed to be done in the areas of time of initiation, duration of exclusive breastfeeding and giving of colostrums to the babies, especially among those delivering outside the hospital.

\section{Limitation}

This study was conducted in the tertiary hospital located in the urban area; thus, may not be a true representation of what is obtainable among the whole population in the state.

\section{References}

[1] Ip, S., Chung, M., Raman, G., Chew, P., Magula, N., De Vine, D., Trikalinos, T. and Lau, J. (2007) Breastfeeding and Maternal and Infant Health Outcomes in Developed Countries. Agency for Healthcare Research and Quality. Evidence Report/Technology Assessment No. 153.

[2] Greer, F.R., Sicherer, S.H. and Burks, A.W. (2008) Effects of Early Nutritional Interventions on the Development of Atopic Disease in Infants and Children: The Role of Maternal Dietary Restriction, Breastfeeding, Timing of Introduction of Complementary Foods, and Hydrolyzed Formulas. Pediatrics, 121, 183-191. https://doi.org/10.1542/peds.2007-3022

[3] Mahr, T.A. (2008) Effect of Breastfeeding on Lung Function in Childhood and Modulation by Maternal Asthma and Atopy. Pediatrics, 122.

[4] Ogbuanu, U.I., et al. (2009) The Effect of Breastfeeding Duration on Lung Function at Age 10 Years: A Prospective Birth Cohort Study. Thorax, 64, 62-66. https://doi.org/10.1136/thx.2008.101543

[5] Federal Ministry of Health (2005) National Policy on Infant and Yong Child Feeding in Nigeria. Federal Ministry of Health, Nutritional Division, Abuja.

[6] World Health Organization: The State of Breastfeeding in 33 Countries 2010. http://www.worldbreastfeedingtrends.org

[7] Pechlivani, F., Vassilakou, T., Sarafidou, J., Zachou, T., Anastasion, C.A. and Sidossis, L.S. (2005) Prevalence and Determinants of Exclusive Breastfeeding during Hospital Stay in Area of Athens, Greece. Acta Paediatrica, 94, 7.

[8] Joshi, P.C., Angdembe, M.R., et al. (2014) Prevalence of Exclusive Breastfeeding and Associated Factors among Mothers in Rural Bangladesh: A Cross-Sectional Study. International Breastfeeding Journal, 9, 7. https://doi.org/10.1186/1746-4358-9-7

[9] Kishore, M.S., Kumor, P. and Aggarwal, A.K. (2009) Breastfeeding Knowledge and Practices amongst Mothers in Rural Population of North India: A Community-Based Study. Journal of Tropical Pediatrics, 55, 183-188. https://doi.org/10.1093/tropej/fmn110 
[10] Tadele, N., Habta, F., Akmel, D. and Deges, E. (2016) Knowledge, Attitude and Practice towards Exclusive Breastfeeding among Lactating Mothers in MizanAman Town, Southwest Ethiopia: Descriptive Cross-Sectional Study. International Breastfeeding Journal, 11, 3. https://doi.org/10.1186/s13006-016-0062-0

[11] Mbwana, H., Coulon, C. and von Hurst, P. (2013) Exclusive Breastfeeding: Mothers Awareness and Healthcare Providers' Practices during Antenatal Visits in Mvomero, Tanzania. International Journal of Nutrition and Metabolism, 5, 40-49.

[12] Owen, C.J., Martin, R.M., Whincup, P.H., Smith, G.D. and Cook, D.G. (2005) Effect of Infant Feeding on the Risk of Obesity across the Life Course: A Quantitative Review of Published Evidence. Pediatrics, 115, 1367-1377. https://doi.org/10.1542/peds.2004-1176

[13] Arenz, S., Rukerl, R., Koletzko, B. and Von Kries, R. (2004) Breastfeeding and Childhood Obesity-A Systematic Review. International Journal of Obesity, 28, 1247-1256. https://doi.org/10.1038/sj.ijo.0802758

[14] Harder, T., Bergmann, R., Lallischnigg, G. and Plagemann, A. (2005) Duration of Breastfeeding and Risk of Overweight: A Meta-Analysis. American Journal of Epidemiology, 162, 397-403. https://doi.org/10.1093/aje/kwi222

[15] Dehinde, A. (2010) Factors Influencing Breastfeeding Practices among Mothers in Lafia Local Government Area of Nasarawa State, Nigeria. PAT, 6, 126-128.

[16] Alade, O., Titiloye, M., Oshiname, F. and Arulogun, O. (2013) Exclusive Breastfeeding and Related Antecedent Factors among Lactating Mothers in a Rural Community in Southwest Nigeria. International Journal of Nursing and Midwifery, 5, 132-138. https://doi.org/10.5897/IJNM2013.0111

[17] Mbada, C., Olowookere, A., Faronbi, J., OyiulolaOyomolaran, F.C., Faremi, F., Ogunlele, A., et al. (2013) Knowledge, Attitude and Techniques of Breastfeeding among Nigerian Mothers from a Semi-Urban Community. BMC Research Notes, 6, 552. https://doi.org/10.1186/1756-0500-6-552

[18] Agho, K., Dibley, M.J., Odiase, J.I. and Ogbonwan, S. (2011) Determinant of Exclusive Breastfeeding in Nigeria. BMC Pregnancy Childbirth, 11, 2. https://doi.org/10.1186/1471-2393-11-2

[19] Agunbiade, O. and Ogunleye, O. (2012) Constraints to Exclusive Breastfeeding Practice among Breastfeeding Mothers in Southwest Nigeria: Implications for Sealing up. International Breastfeeding Journal, 7, 5-10. https://doi.org/10.1186/1746-4358-7-5

[20] Salamni, L. (2006) Factors Influencing Breastfeeding Practices in Edo State, Nigeria. African Journal of Food Agriculture Nutrition and Development, 6, 1-12.

[21] Ojofeitimi, E.O., Egimai, O.A., Owolabi, O.O., Oluwabusi, O. and Olanuga, T.O. (2000) Breastfeeding Practices in Urban and Rural Health Centres: Impact of Baby Friendly Hospital Initative in Ile-Ife, Nigeria. Nutrition and Health, 14, 119-125.

https://doi.org/10.1177/026010600001400204 


\section{Questionaire}

\section{Demographic characteristics of participants}

Age (years)............ Parity.......... Occupation....... Religion........

Educational status......... Marital status....

Where did you get information on breastfeeding?

Media......... Friends. Church . Hospital....... Relatives

\section{Breastfeeding practices}

Did you practice exclusive breastfeeding?.........yes/no? How long.

For how many children.......... Was it enough for the baby yes/no?

Will you do it again ..yes/no?

Time of initiation...........Duration per feed .... .Frequency

Complementary food introduced at..... Total duration of breastfeeding

The first milk (colostrums). Given to baby/Discarded?

Give reason.

Reason for breastfeeding

It is the social norm

Child spacing

Healthy growth of baby

Natural immunity for baby

Easy and comfortable

Returns the body to normal

Encouragement from relatives

Pressure from relatives

\section{Reason for discontinuation}

Baby continues to be hungry Baby was losing weight Maternal health problem Became pregnant

Pain in the breast It was time to discontinue Inadequate milk production Return to work/school Lack of support (husband)

It is too tiring

Baby refused

\section{Place of last delivery}

With TBA, maternity home, private hospital, secondary health center, tertiary health centre

\section{Mode of delivery}

Spontaneous vertex delivery, operative vaginal delivery, Caesarean Section 
Submit or recommend next manuscript to SCIRP and we will provide best service for you:

Accepting pre-submission inquiries through Email, Facebook, LinkedIn, Twitter, etc. A wide selection of journals (inclusive of 9 subjects, more than 200 journals)

Providing 24-hour high-quality service

User-friendly online submission system

Fair and swift peer-review system

Efficient typesetting and proofreading procedure

Display of the result of downloads and visits, as well as the number of cited articles

Maximum dissemination of your research work

Submit your manuscript at: http://papersubmission.scirp.org/

Or contact ojog@scirp.org 